\title{
ANALISA KEKUATAN PADA POROS RODA DEPAN MOTOR HONDA BLADE 110R TAHUN 2010 DENGAN MATERIAL St90 JIS SCM 447-AISI 4340
}

\author{
Alharisy Aji ${ }^{1, a}$, Kardiman ${ }^{2, b}$, Jojo sumarjo $^{3, c}$, Muhammad Alfi Alfaridzi ${ }^{4, d}$ \\ 1,2,3,4 Mechanical Engineering Study Program, Faculty of Engineering, University Of \\ Singaperbangsa Karawang JI. HS.Ronggo Waluyo, Puseurjaya, Karawang, 41361, \\ Indonesia \\ aalharisy.2872@gmail.com, bkardiman@ft.unsika.ac.id, cjojo sumarjo@ft.unsika.ac.id
}

\begin{abstract}
Abstrak.
Poros adalah salah satu komponen sepeda motor , dimana poros merupakan salah satu bagian yang terpenting dari setiap mesin. Peranan utama sebuah poros adalah untuk mentransmisikan daya dari satu elemen mesin ke bagian elemen mesin lainnya. Daya tersebut dihasilkan oleh gaya tangensial dan momen torsi yang hasil akhirnya adalah daya tersebut akan ditransmisikan kepada elemen lain yang terhubung dengan poros tersebut.. Sehingga di perlukan poros yang baik untuk mencapai fungsi dari poros tersebut. Poros roda merupakan salah satu komponen yang saangat penting dari sebuah sepeda motor karena poros berfungsi untuk menopang body, beban kendaraan itu sendiri maupun beban luar pada kendaraan dalam hal ini manusia atau barang muatan pada sepeda motor. Sehingga di perlukan poros yang baik untuk mencapai fungsi dari poros tersebut. Dipenelitian ini kita membahas tentang Poros dengan beban puntir dan lentur yang bertujuan untuk memberikan pengetahuan tentang poros depan, Lebih menambah wawasan pengetahuan dalam bidang otomotif dan Mampu merencanakan secara sistematis elemen-elemen mesin yang ada pada system kerja poros. pada penelitian ini poros di berikan Beban Luar yaitu Berat Motor $104 \mathrm{~kg}$, Berat badan pengendara $64 \mathrm{~kg}$, sehingga berat total motor $164 \mathrm{~kg}$, pada Perhitungan Diameter Poros didapat tegangan normal maksimum 1441,45 Mpa, saftey of factor 6.24371, Diameter poros $9.9 \mathrm{~mm}$ Besar defleksi $5.16854 \mathrm{x}$ $10^{\wedge}(-5) \mathrm{m}$ Berdasarkan hasil perhitungan dapat diambil bahwa dimensi poros atau diameter hasil perhitungan adalah 9.9. $\mathrm{mm}$, aman untuk digunakan dan kurang $0.1 \mathrm{~mm}$ dengan diameter ukuran sebenarnya yaitu $10 \mathrm{~mm}$. Dan defleksi yang di terima poros sebesar 5.16854 x 10-5 m atau 0.0516854 $\mathrm{mm}$.
\end{abstract}

Kata kunci. poros, beban puntir, beban lentur, pembebanan pada poros, poros roda depan, gaya geser, momen lentur

\section{Abstract.}

The shaft is one of the components of a motorcycle, where the shaft is one of the most important parts of every engine. The main role of a shaft is to transmit power from one machine element to another. The power is generated by the tangential force and the torque moment which the end result is that the power will be transmitted to other elements connected to the shaft. So, a good shaft is needed to achieve the function of the shaft. The wheel axle is one of the most important components of a motorcycle because the shaft serves to support the body, the load of the vehicle itself and the external load on the vehicle in this case humans or cargo on a motorcycle. So in need of a good shaft to achieve the function of the shaft. In this study, we discuss about the axle with torsional and flexural loads which aim to provide knowledge about the front axle, increase knowledge in the automotive field and be able to systematically plan the engine elements in the shaft work system. in this study the shaft was given an external load, namely the motor weight $104 \mathrm{~kg}$, the rider's weight $64 \mathrm{~kg}$, so the total weight of the motor was $164 \mathrm{~kg}$, the shaft diameter calculation obtained a maximum normal stress of $1441.45 \mathrm{MPa}$, safety of factor 6.24371 , shaft diameter $9.9 \mathrm{~mm}$ large deflection $5.16854 \times 10^{\wedge}(-5) \mathrm{m}$ Based on the calculation results it can be concluded that the shaft dimension or the calculated diameter 
is $9.9 . \mathrm{mm}$, safe to use and $0.1 \mathrm{~mm}$ less than the actual size diameter of $10 \mathrm{~mm}$. And the deflection received by the shaft is $5.16854 \times 10-5 \mathrm{~m}$ or $0.0516854 \mathrm{~mm}$.

Keywords: axle, torsional load, bending load, load on axle, front axle, shear force, bending moment

\section{Pendahuluan}

Bidang teknologi khususnya kendaraan bermotor atau otomotif di dalam negeri semakin bertumbuh dengan pesat, terutama sepeda motor di indonesia yang di pakai dan digunakan sebagai alat transfortasi utama bagi seluruh lapisan masyarakat. Namun sering kali kita jumpai sepeda motor cepat ruksak, tenaga yang tidak optimal dan umur pakai yang tidak lama misalnya sering ganti suku cadang atau onderdil salah satunya seperti poros roda Honda Blade 110R Tahun 2010.

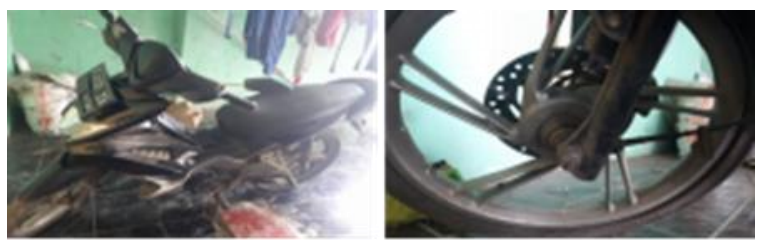

Gambar 1. Honda Blade 110R Tahun 2010

Poros adalah salah satu elemen penting dari sebuah rancangan mesin khususnya pada kendaraan bermotor seperti mobil dan sepeda motor karena poros memiliki fungsi sebagai as roda yang menopang beban mesin dan seluruh beban kendaraan tersebut dan beban dari luar seperti pengemudi atau jumalah barang bawaan yang di angkut pada sepeda motor, sehingga diperlukan poros yang baik untuk mencapai fungsi dari poros diatas [1] [2]

\section{Tinjauan Pustaka}

\section{Poros}

Secara umum Poros adalah suatu bagian batang bula yang bekerja sebagai penyalur daya dengan cara stasioner yang beputar, biasanya terpasang pada elemen-elemen seperti roda gigi, pulley, kopling, as roda dan elemen pemindah lainnya. Poros dapat menerima beberapa bentuk pembebanan tergantung penempatan dan kegunaannya seperti beban lenturan, beban tarikan, beban tekan atau beban puntiran yang bekerja satu dengan lainnya. [2]

\section{Prinsip kerja poros}

Merupakan elemen terpenting dari sebuah mesin adalah poros. Umumnya mesin menyalurkan daya dengan menggunakan putaran poros. Fungsi dari transmisi itu menggunakan poros. Poros yang bekerja meneruskan daya dari trnsmisi ke difrensial dalam keadaan tidak satu garis tegak lurus sering disebut juga poros gardan atau propellar. Dan putaran diteruskan dari transmisi ke poros gardan dan dari poros ke diferensial melalui universal joint, fungsi dari universal joint yaitu meneruskan putaran daya dalam keadaan tidak satu garis. [2] [3].

\section{Klasifikasi poros}

Menurut bentuk dan pembebanannya poros diklasifikasikan menjadi beberapa jenis sebagai berikut :

a) poros transmisi

Poros transmisi mendapat pembebanan puntir murni atau pembebanan puntir dan lentur sekaligus. Proses penyaluran Daya dilakukan melalui kopling, roda gigi, puli sabuk atau sproket rantai dan lainlain menuju poros . Contoh pada mesin yang mengalami beban puntir murni yaitu gardan [3] 


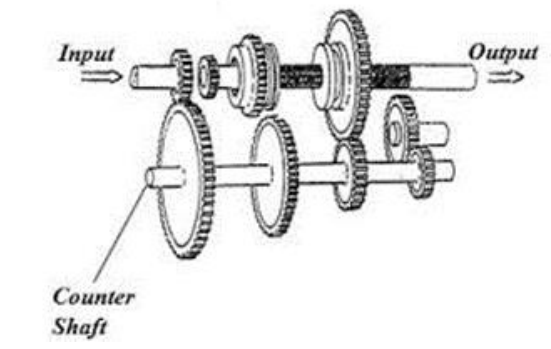

\section{Gambar 2. Poro- poros transmisi}

b) Poros spindel

Poros spindle adalah jenis poros transmisi yang mrmiliki dimensi cenderung pendek, seperti pada poros utama mesin perkakas, dimana beban utamanya merupakan beban puntiran, disebut spindel. Syarat yang harus dipenuhi poros spindel ini adalah deformasinya kecil, sebab apabila deformasinya besar benda kerja tidak akan silindris. Serta bentuk dan ukuran harus teliti. Poros spindel berhubungan langsung dengan terhadap benda kerja [4]

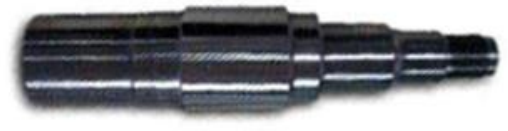

\section{Gambar 3. Poros spindel}

c) Poros Gandar

Pada poros jenis ini pembebanan hanya lentur, terkecuali jika digerakan oleh penggerak mula dia akan mengalami pembebanan punter juga. Menurut bentuknya, poros dapat diklaifikasikan dari poros lurus umum, poros engkol yang digunakan sebagai poros utama mesin torak. Poros luwes di peruntukan sebagai transmisi daya yang relative kecil supaya bisa mendapat kebebasan dari perubahan arah, dan lain-lain

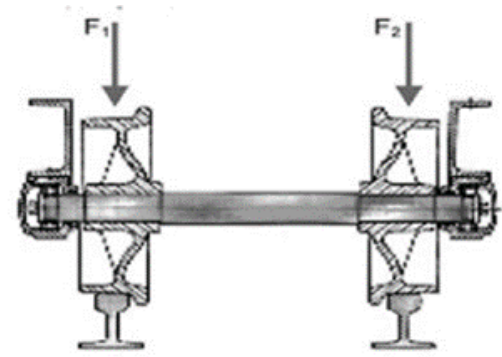

Gambar 4. Poros gandar

Spesifikasi Poros Roda Depan Motor Honda Blade 110R Tahun 2010

- Panjang Poros

- Diameter Poros

- Material Poros
$: 176.1 \mathrm{~mm}$

: $10 \mathrm{~mm}$

: Baja Karbon Konstruksi Mesin St90 JIS SCM 447 - AISI 4340 


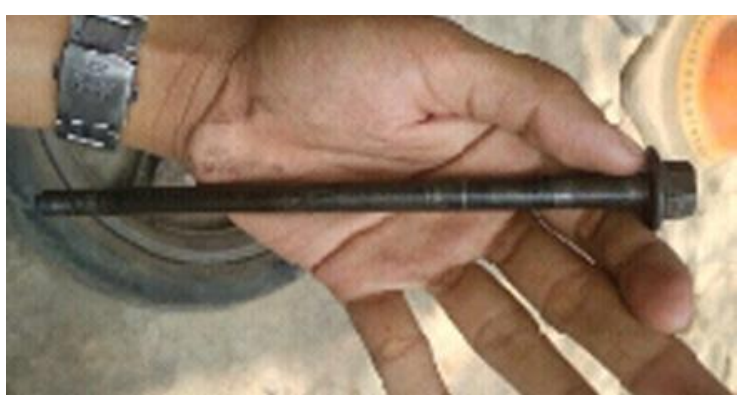

Gambar 4. Poros roda Motor Honda Blade 110R

Gambar 2D dan 3D Elemen Mesin
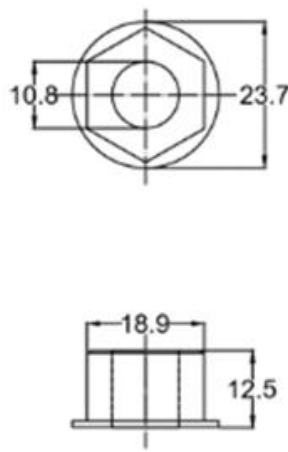

Gambar 5. mur 2D
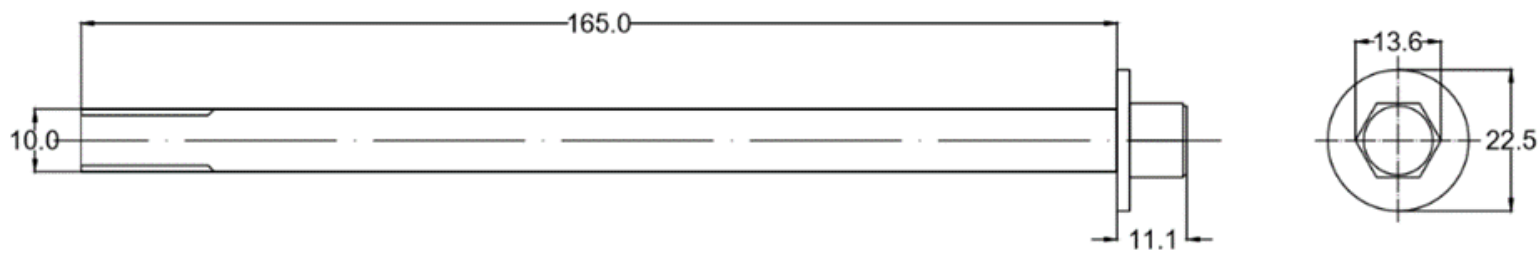

Gambar 5. Poros 2D

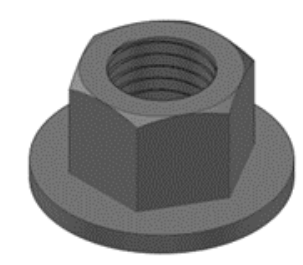

Gambar 6. Mur 3D

Gambar 6. Poros 3D 
Tabel 1. Komposisi Kimia St90 JIS SCM 447 - AISI 4340 [1]

\begin{tabular}{|l|c|}
\hline \multicolumn{1}{|c|}{ Chemistry } & Kadar (\%) \\
\hline Chromium, $\mathrm{Cr}$ & $0.80-1.10$ \\
\hline Manganese, $\mathrm{Mn}$ & $0.75-1.0$ \\
\hline Carbon, $\mathrm{C}$ & $0.380-0.430$ \\
\hline Silicon, $\mathrm{Si}$ & $0.15-0.30$ \\
\hline Molybdenum, Mo & $0.15-0.25$ \\
\hline Sulfur, $\mathrm{S}$ & 0.040 \\
\hline Phosphorous, $P$ & 0.035 \\
\hline Iron, $\mathrm{Fe}$ & Balance \\
\hline
\end{tabular}

Tabel 2. Sifat Fisika St90 JIS SCM 447 - AISI 4340

\begin{tabular}{|l|c|c|}
\hline \multicolumn{1}{|c|}{ Properties } & Metric & Imperial \\
\hline Density & $7.85 \mathrm{~g} / \mathrm{cm}^{3}$ & $0.284 / \mathrm{in}^{3}$ \\
\hline
\end{tabular}

Tabel 3. Mechcanial Properties St90 JIS SCM 447 - AISI 4340

\begin{tabular}{|l|c|c|}
\hline \multicolumn{1}{|c|}{ Properties } & Metric & Imperial \\
\hline Tensile strength & $655 \mathrm{MPa}$ & $95000 \mathrm{psi}$ \\
\hline Yield strength & $415 \mathrm{MPa}$ & $60200 \mathrm{psi}$ \\
\hline Bulk modulus (typical for steel) & $140 \mathrm{GPa}$ & $20300 \mathrm{ksi}$ \\
\hline Shear modulus (typical for steel) & $80 \mathrm{GPa}$ & $11600 \mathrm{ksi}$ \\
\hline Elastic modulus & $190-210 \mathrm{GPa}$ & $\begin{array}{c}27557-30458 \\
\mathrm{ksi}\end{array}$ \\
\hline $\begin{array}{l}\text { Poisson's ratio } \\
\text { Elongation at break (in 50 mm) }\end{array}$ & $0.27-0.30$ & $0.27-0.30$ \\
\hline Hardness, Brinell & $25.70 \%$ & $25.70 \%$ \\
\hline Hardness, Knoop (converted from Brinell hardness) & 2197 & 197 \\
\hline $\begin{array}{l}\text { Hardness, Rockwell B (converted from Brinell } \\
\text { hardness) }\end{array}$ & 92 & 219 \\
\hline $\begin{array}{l}\text { Hardness, Rockwell C (converted from Brinell } \\
\text { hardness. } \\
\text { Value below normal HRC range, for comparison } \\
\text { purposes only) }\end{array}$ & 13 & 13 \\
\hline Hardness, Vickers (converted from Brinell hardness) & 207 & 207 \\
\hline $\begin{array}{l}\text { Machinability (based on AISI 1212 as 100 } \\
\text { machinability) }\end{array}$ & 65 & 65 \\
\hline
\end{tabular}

\section{Hasil Dan Pembahasan}

\section{Perhitungan beban dari luar}
- Jarak antar roda (L)
$=1.227 \mathrm{~mm}$
- Berat Motor
$=104 \mathrm{~kg}$
- Berat badan pengendara
$=64 \mathrm{~kg}$
- Berat total motor
$=164 \mathrm{~kg}$ 
- Daya maximum mesin $\quad=8,4$ PS di $7.500 \mathrm{rpm}$

- Top Speed

$$
=100 \mathrm{~km} / \mathrm{jam}
$$

- Koefisien gesekan statis di antara roda dengan aspal $(\mu)=0,3$
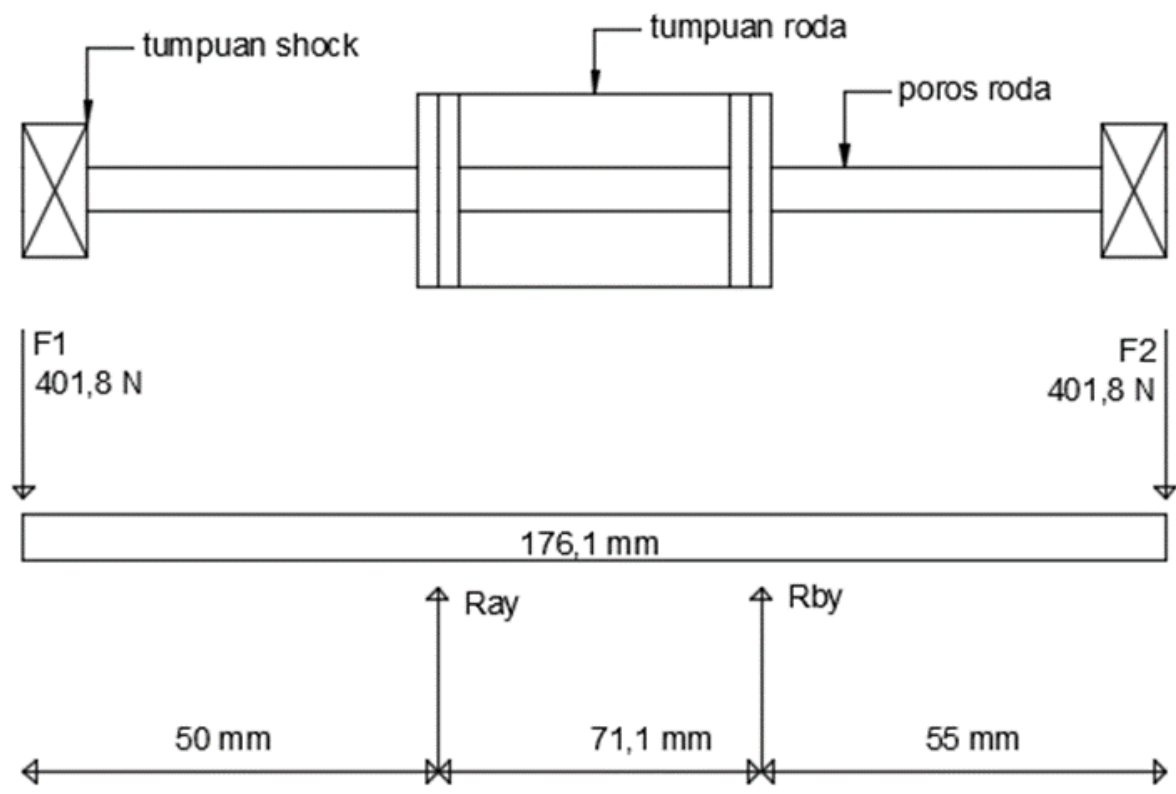

\section{Gambar 7. DBB gaya yang terjadi pada poros}

hasil perhitungan maka :

kaerena berat total didistribusikan pada dua roda depan dan belakang motor maka didapat berat beban pada poros depan adalah $82 \mathrm{~kg}$, maka dapat di hitung dari masing 2 tumpun as roda depan $\mathrm{m} 1 \mathrm{dan} \mathrm{m} 2$ Honda Blade 110R Tahun 2010 adalah.

$$
\begin{aligned}
\mathrm{m} 1=\mathrm{m} 2 & =\frac{82}{2} \\
& =41 \mathrm{~kg}
\end{aligned}
$$

untuk mengidentifikasi berapa besar gaya yang diterima poros roda perhitungan dilakukan Dengan menggunakan rumus [4] [5] :

$$
\begin{aligned}
\mathrm{W} & =\mathrm{m} \times \mathrm{g} \\
\mathrm{W} & =41 \times 9,8 \\
\mathrm{~W} & =401.8 \mathrm{~N}
\end{aligned}
$$

\section{Menentukan Reaksi- reaksi yang terjadi pada batang poros}

$$
\begin{aligned}
\sum F X & =0 \\
\sum F Y & =0 \\
-F 1+R B Y+R A Y-F 2 & =0 \\
-401.8+\mathrm{RBY}+\mathrm{RAY}-401.8 & =0 \\
\mathrm{RBY}+\mathrm{RAY} & =803.6 \mathrm{~N} \\
\sum \mathrm{M} \mathrm{A} & =0 \\
\mathrm{RBY}(\mathrm{R})+\mathrm{F} 2(\mathrm{R})-\mathrm{F} 1(\mathrm{R}) \quad & =0
\end{aligned}
$$




$$
\begin{aligned}
401.8(126,1)+\operatorname{RBY}(71,1)-401.8(50) & =0 \\
30,576,98-\operatorname{RBY}(71,1)+\frac{30,576.98}{71,1} & =0 \\
\text { RBY } & =430.055 \mathrm{~N}
\end{aligned}
$$

Sehingga diperoleh nilai RBY sebesar :

\section{$\mathrm{RBY}=\mathbf{4 3 0 . 0 5 5} \mathrm{N}$}

Untuk mendapat nilai RAY menggunakan Persamaan awal yaitu :

$$
\begin{array}{ll}
\text { RAY + RBY } & =803.6 \mathrm{~N} \\
\text { RAY }-430.055 \mathrm{~N} & =803.6 \mathrm{~N}
\end{array}
$$

Maka didapat nilai sebesar :

RAY $=373.544 \mathrm{~N}$

\section{- Step 1}

$$
0 \leqslant x \leqslant 50 \mathrm{~mm}
$$

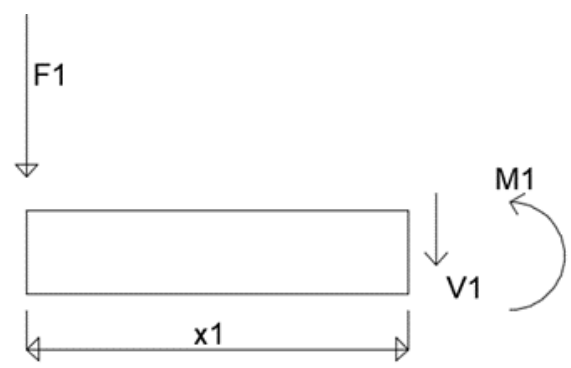

Gambar 8. DBB potongan 1 poros

$$
\begin{aligned}
\sum \mathrm{FY} & =0 \\
-\mathrm{F} 1-\mathrm{V}_{1} & =0
\end{aligned}
$$

Maka gaya geser yang diperoleh sebesar :

$$
\begin{aligned}
& \mathrm{V}_{1}=-401.8 \mathrm{~N} \\
& \sum \mathrm{M}_{1}=0 \quad \text { Dinyatakan bahwa } \quad<=(+) \quad \Rightarrow(-) \\
& \mathrm{F} 1(\mathrm{X})+\mathrm{M}_{1}=0 \\
& \mathrm{M}_{1}=-\mathrm{F} 1 .(\mathrm{X}) \\
& M_{1}=-401.8(0)=0 \quad X=0, \\
& M_{1}=-401.8(50)=-20,090 \mathrm{Nmm} \quad X_{1}=50 \mathrm{~mm}
\end{aligned}
$$

\section{- Step 2}

$50 \mathrm{~mm} \leq \mathrm{x}_{2} \leq 121.1 \mathrm{~mm}$

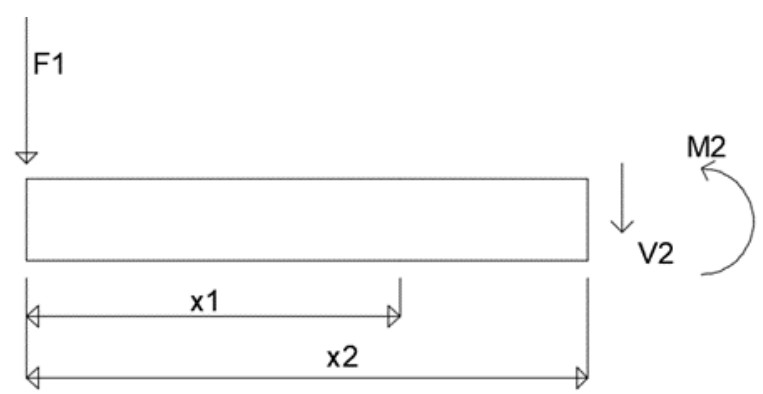

Gambar 9. DBB potongan 2 poros 


$$
\begin{aligned}
\sum F Y & =0 \\
-F_{1}+\text { RAY }-V_{1} & =0 \\
V_{2} & =-F_{1}+\text { RAY } \\
V_{2} & =-401.8 \mathrm{~N}+373.544 \mathrm{~N} \\
V_{2} & =-28.256 \mathrm{~N}
\end{aligned}
$$

Gaya geser yang diperoleh sebesar: $28.256 \mathrm{~N}$

$$
\begin{aligned}
\sum \mathrm{M}_{=} \quad \text { Dinyatakan bahwa } & : \quad<=(-) \quad \Rightarrow(+) \\
-\mathrm{F} 1\left(\mathrm{X}_{2}\right)+\mathrm{RAY}\left(\mathrm{X}_{2}-50\right)-\mathrm{M}_{2} & =0 \\
\mathrm{M}_{2} & =-401.8 \mathrm{~N} \mathrm{X}_{2}+373.544\left(\mathrm{X}_{2}-50\right) \quad \mathrm{X}_{2}=121.1 \mathrm{~mm} \\
\mathrm{M}_{2} & =-401.8(121.1)+373.544(121.1-50) \\
\mathrm{M}_{2} & =-22,099.0016 \mathrm{Nmm}
\end{aligned}
$$

Maka didapat nilai momen lentur 2 sebesar $=-22.099,0016 \mathrm{Nmm}$ atau $-22,0099 \mathrm{Nm}$

\section{- Step 3}

$$
121.1 \mathrm{~mm} \leq \mathrm{x} \leq 176.1 \mathrm{~mm}
$$

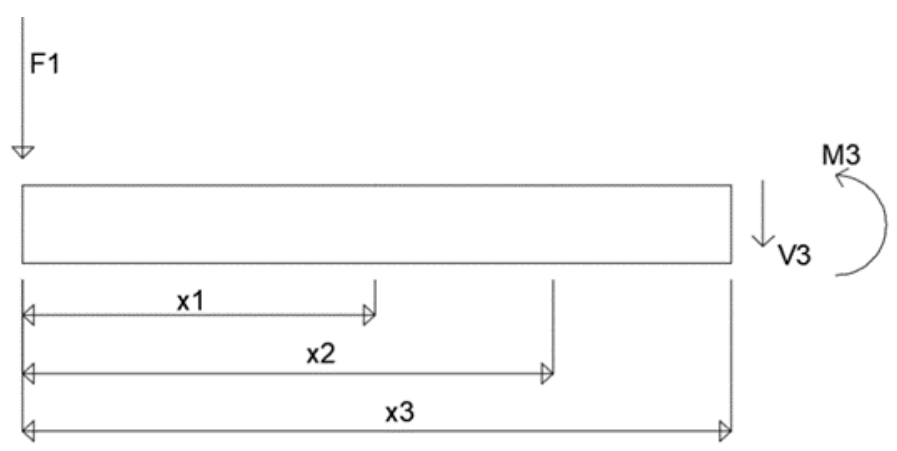

Gambar 10. DBB potongan 3 poros

$$
\begin{aligned}
& \sum F Y=0 \\
& -\mathrm{V}_{3}-\mathrm{F} 1+\mathrm{RAY}+\mathrm{RBY}=0 \\
& \mathrm{~V}_{3}=\mathrm{RAY}+\mathrm{RBY}-\mathrm{F} 1 \\
& \mathrm{~V}_{3}=373.544 \mathrm{~N}+430.055 \mathrm{~N}-401.8 \mathrm{~N} \\
& \mathrm{~V}_{3}=401.799 \mathrm{~N}
\end{aligned}
$$

Gaya geser yang diperoleh sebesar : $401.799 \mathrm{~N}$

$$
\begin{aligned}
& \sum \mathrm{M}_{3}=0 \quad\langle=(-) \quad=>(+) \\
& -\mathrm{F} 1\left(\mathrm{X}_{3}\right)+\mathrm{RAY}\left(\mathrm{X}_{3}-50\right)+\mathrm{RBY}\left(\mathrm{X}_{3}-121.1\right)-\mathrm{M}_{3}=0 \\
& \mathrm{M}_{3}=-401.8\left(\mathrm{X}_{3}\right)+373.544\left(\mathrm{X}_{3}-50\right)+430.055\left(\mathrm{X}_{3}-121.1\right) \\
& \mathrm{X}_{3}=176.1 \mathrm{~mm} \\
& \mathrm{M}_{3}=-401.8(176.1)+373.544(176.1-50)+430.055(176.1-121.1) \\
& \mathrm{M}_{3}=141,513.9034 \mathrm{Nmm} \\
& \mathrm{M}_{3}=141.5139 \mathrm{Nm}
\end{aligned}
$$

Maka didapat nilai momen lentur 3 sebesar $141.5139 \mathrm{Nm}$

\section{Diagram momen dan gaya}

\section{- Diagram Gaya Geser}

dari hasil perhitungan reaksi-reaksi yang bekerja pada batang poros maka di dapat diagram gaya geser sebagai berikut

V3 
V1 $=-401.8 \mathrm{~N}$

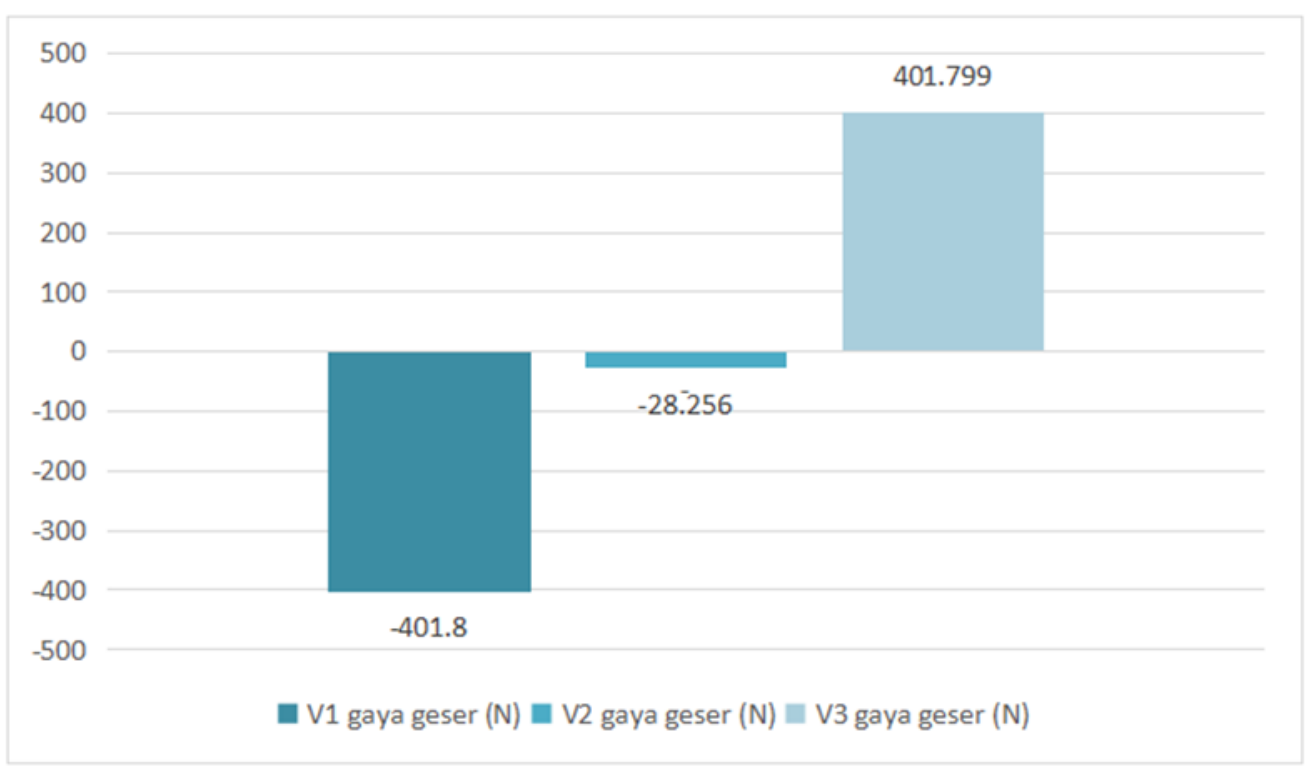

Gambar 11. Diagram gaya geser

\section{- Diagram Momen Lentur}

dari hasil perhitungan reaksi-reaksi yang bekerja pada batang poros maka di dapat diagram momen lentur sebagai berikut

M3

$$
=141.5139 \mathrm{Nm}
$$

M2 $=-22.0990 \mathrm{Nm}$

M1 $=-0.2009 \mathrm{Nm}$

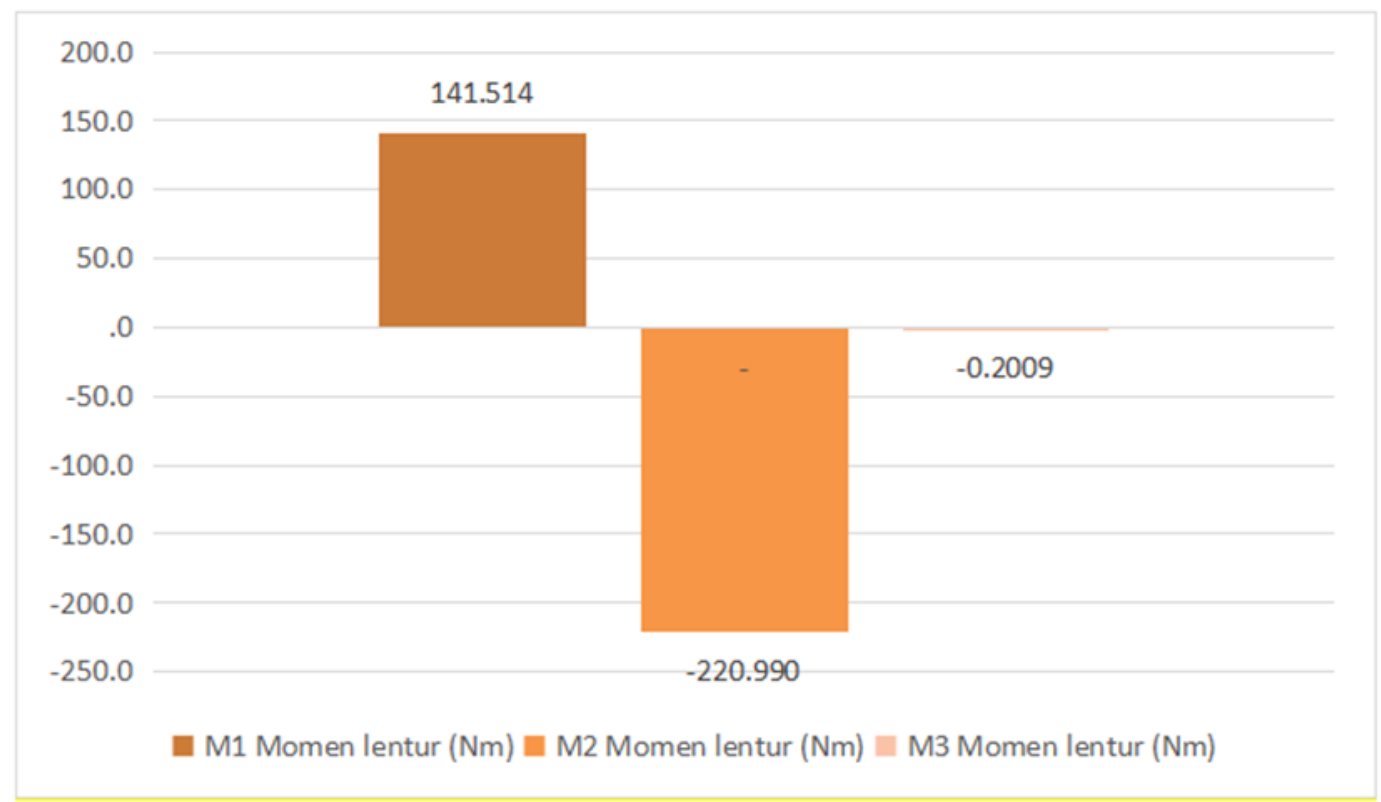

\section{Gambar 11. Diagram momen lentur}

\section{Perancangan diameter poros}

- Menghitung tegangan normal akibat momen puntir atau torsi( $\left.\tau_{-} \mathbf{N}\right)$

Rumus inersia sudut poros [4] :

$$
I_{s}=\frac{\pi D^{4}}{32}
$$




$$
\begin{aligned}
& I_{s}=\frac{3,14 \times(0.01 \mathrm{~mm})^{4}}{64} \\
& I_{s}=4.90874 \times 10^{-10} \mathrm{~m}^{4}
\end{aligned}
$$

Keterangan :

$I_{S} \quad$ : inersia sudut poros $\left(\mathrm{mm}^{4}\right)$

$\mathrm{D}$ : diameter poros $(\mathrm{mm})$

Rumus tegangan geser akibat torsi :

$$
\begin{aligned}
\tau_{N} & =\frac{T \times \frac{c}{2}}{I_{S}} \\
\tau_{N} & =\frac{141.5139 \mathrm{Nm} \times 0.05 \mathrm{~m}}{4.90874 \times 10^{-10} \mathrm{~m}^{4}} \\
\tau_{N} & =144144831 \mathrm{~N} / \mathrm{m}^{2} \\
\tau_{N} & =144,144831 \mathrm{MPa}
\end{aligned}
$$

Besar Tegangan Normal yang terjadi adalah sebesar 144,144831 MPa Keterangan :

$$
\begin{array}{ll}
\tau_{N} & : \text { tegangan normal }\left(\mathrm{N} / \mathrm{mm}^{2}\right) \\
\mathrm{T} & : \text { momen puntir }(\mathrm{Nmm}) \\
\mathrm{C} & : \text { titik berat }(\mathrm{mm}) \\
I_{S} & : \text { inersia sudut poros }\left(\mathrm{mm}^{4}\right)
\end{array}
$$

- Menghitung tegangan normal maksimum

$$
\begin{aligned}
\tau_{\text {max }} & =\frac{32 T}{\pi D^{3}} \\
\tau_{\text {max }} & =\frac{32(141.5139 \mathrm{Nm})}{\pi(0.01)^{3}} \\
\tau_{\text {max }} & =1,44145 \times 10^{9} \mathrm{~N} / \mathrm{m}^{2} \\
\tau_{\text {max }} & =1441,45 \mathrm{MPa}
\end{aligned}
$$

- Menghitung saftey of factor

$$
\begin{aligned}
S_{f} & =\frac{\sigma_{b}}{\tau_{\alpha}} \\
S_{f} & =\frac{9 \times 10^{6} \mathrm{~N} / \mathrm{m}^{2}}{144145 \mathrm{~N} / \mathrm{m}^{2}} \\
S_{f} & =6.24371
\end{aligned}
$$

Keterangan :

$\tau_{\alpha}$ : tegangan geser ijin $\left(\mathrm{N} / \mathrm{mm}^{2}\right.$ atau $\left.\mathrm{kg} / \mathrm{mm}^{2}\right)$

$\sigma_{b} \quad:$ kekuatan tarik $\left(\mathrm{kg} / \mathrm{mm}^{2}\right)$

$S_{f} \quad$ : Faktor keamanan

- Menghitung diameter

$$
D=\sqrt[3]{\frac{32 x F S x T}{\pi S y}}
$$




$$
\begin{aligned}
& D=\sqrt[3]{\frac{32 \times 6.24371 \times 141.5139 \mathrm{Nm}}{\pi 9 \times 105}} \\
& \mathrm{D}=0.099 \mathrm{~m} \\
& \mathrm{D}=9.9 \mathrm{~mm}
\end{aligned}
$$

Besar diameter setelah perhitungan yaitu $9.9 \mathrm{~mm}$

Keterangan :

$$
\begin{aligned}
& F S=\text { Safety factor } \\
& D=\operatorname{diameter}(m)
\end{aligned}
$$

\section{- Menghiung defleksi}

$$
\begin{aligned}
& \delta=\frac{4 W L^{3}}{3 E \pi D^{4}} \\
& \delta=\frac{4820(o .1761)^{3}}{3 E \pi(9.9)^{4}} \\
& \delta=5.16854 \times 10^{-5}
\end{aligned}
$$

Besar Defleksi yang terjadi pada poros sebesar $\delta=5.16854 \times 10^{-5} \mathrm{~m}$

Keterangan :

$$
\delta=\text { Defleksi m }
$$

\section{Kesimpulan}

Poros yang dirancang menggunakan material St90 JIS SCM 447 - AISI 4340 ini diperuntukan untuk menompang sebuah beban massa motor dan beban massa penumpang yang diposisikan pada roda depan pada sepeda motor Honda Blade 110cc.

Ada beberapa hasil perhitungan yang di dapat diantaranya adalah

- tegangan normal maksimum $=1441,45 \mathrm{MPa}$

- $\quad$ saftey of factor

$$
\begin{aligned}
& =6.24371 \\
& =9.9 \mathrm{~mm} \\
& =5.16854 \times 10^{-5} \mathrm{~m}
\end{aligned}
$$

- Besar defleksi

Berdasarkan hasil perhitungan dapat diambil kesimpulan bahwa dimensi poros atau diameter hasil perhitungan di atas adalah 9.9. $\mathrm{mm}$, aman untuk digunakan dan kurang $0.1 \mathrm{~mm}$ dengan diameter ukuran sebenarnya yaitu $10 \mathrm{~mm}$. Dan defleksi yang di terima poros sebesar $5.16854 \mathrm{x} 10-5 \mathrm{~m}$ atau $0.0516854 \mathrm{~mm}$.

\section{Daftar pustaka}

[1] T. Dwi putra, variasi bahan material dan ukuran diameter poros dengan menggunakan metode pengujian puntir, Widya Teknika, 2014 vol.22 no22.

[2] S. Hery, perancangan elemen mesin, Bandung: alfabeta, 2014.

[3] J. K. N. Richard G. Budynas, Shigley's Mechanical Engineering Design, McGraw-Hill Education, 2015.

[4] Kementerian pendidikan dan kebudayaan republik indonesia, pemeliharaan sasis dan pemindah tenaga kendaraan ringan, jakarta, 2012.

[5] S. D. K. Suga, Dasar Perencanaan dan Pemilihan Elemen Mesin, jakarta: PT. pradya Paramita, 1991.

[6] P. Z. Astamar, MEKANIKA TEKNIK (Machine of Materials) edisi ke dua. 